\title{
Volto já (Be right back), de Black Mirror: tecnologias, finitude e a arte de saber terminar
}

\author{
Maria Cristina Franco Ferraz \\ https://orcid.org/0000-0001-5142-8734 \\ I - UFRJ \\ Rio de Janeiro (RJ), Brasil
}

Resumo: A partir de uma retomada detalhada e comentada do episódio Volto já da série Black Mirror, o artigo discute a agenda atual da tecnociência em sua inflexão fáustica, com base nos trabalhos seminais de Hermínio Martins. Convoca, a seguir, José Gil para relacionar o impulso fáustico ao fechamento da porosidade da pele e à corrosão de Eros. Por fim, remete à proposta nietzschiana da arte de saber terminar como um contraponto aos sofrimentos com relação à perda e à finitude, tema central do episódio Volto já, de Black Mirror.

Palavras-chave: Black-Mirror; inflexão fáustica da tecnologia; cultura contemporânea; finitude.

\begin{abstract}
Black Mirror's episode Be right back: technologies, finitude, and the art of finding an end - The paper analyses Black Mirror's episode Be right Back in order to discuss certain contemporary issues concerning the technological agenda. It highlights its Faustic inflexion such as emphasized by the Portuguese sociologist Hermínio Martins, and relates this question to José Gil's investigations on the closure of the porosity of the skin, as well as its effects on the corrosion of Eros. Finally, it refers to the Nietzschean art of finding an end as a counterpoint to the sufferings related to loss and finitude, which constitute the central problem explored in Be right back.
\end{abstract}

Keywords: Black Mirror; Faustic notion of technology; contemporary culture; finitude.

O episódio Volto já (Be right back), que abriu a segunda temporada da série Black Mirror, tematiza a problemática da perda e da finitude na cultura ocidental contemporânea. Retomemos detalhadamente seu enredo para, a seguir, aprofundarmos as questões que ele levanta. Um casal jovem vive uma relação amorosa bem realizada, em uma casa 
de campo que tinha pertencido aos pais do rapaz. Ela se chama Marta; ele, Ash, literalmente, cinza. O nome do personagem já prediz sua sina: tornar-se cinza, pela morte prematura. Mas também aponta para seu futuro renascer, tal como uma ciberfênix.

Nas primeiras cenas, sentado em uma van, Ash aguarda Marta, que tinha ido comprar um lanche na noite chuvosa. Quando a moça retorna ao carro com o lanche, vê-se que Ash está constantemente distraído, desatento, sugado pela tela do celular. Em outra cena, já em casa, verificando a desatenção de Ash, Marta diz que o celular do companheiro é um ladrão, pois rouba sua atenção. Ainda que no episódio isso não seja diretamente evidenciado, provavelmente este ladrão irá roubar a própria vida do personagem.

Com efeito, Ash morre no caminho para devolver a van alugada, sem ter a seu lado a mulher, que frequentemente chamava atenção para seu sequestro constante pelas sedutoras telas do celular. O enredo sugere essa ilação, pois na cena inicial no carro, quando Ash vai dar a partida, Marta pede-lhe para guardar o celular no porta-luvas. Sua frase curta soa imperativa: porta-luvas. Atesta, assim, que a moça sempre mandava Ash fazer isso quando usavam o carro. Na sequência, já em casa, lembra a ele onde o celular ficara. A redundância desse detalhe favorece a sugestão sobre o motivo da morte no carro, por provável distração on-line.

Outra pista sobre a morte iminente de Ash, e sobre a própria temática do episódio, está presente nas músicas que o casal ouve e canta no início, ainda no carro - duas canções dos Bee Gees -, mesmo em um tom de certo modo paródico, retrô. Uma delas é If I can't have you, jura pop de amor eterno, que nem a morte é capaz de dissolver. Felizes na noite de chuva, cantam juntos no carro o refrão If I can't have you/I don't want nobody, baby/If I can't have you, uh-huh, oh. Ainda nas cenas iniciais na van, outro hit dos Bee Gees comparece, mesmo que de modo irônico. Trata-se de How deep is your love, outra referência pop que celebra a profundidade do amor insubstituível. Como em outros episódios da série Black Mirror, a cultura pop (nesse caso, dos anos 70 do século passado) funciona como pano de fundo e horizonte culturais. No lugar da longa tradição sobre amor inscrita na cultura letrada ocidental, a referência pop é introduzida, servindo como matriz pedagógica acerca dos verdadeiros vínculos amorosos. Vínculos profundos, insubstituíveis, sempre de algum modo assombrados pela possibilidade de perda ou morte.

Vejamos como o tema é introduzido de modo explícito no episódio. Chegando em casa, Ash observa uma foto emoldurada, que ele fotografa para compartilhar em seu celular. Explica a Marta que se trata de Jack, seu irmão que morreu ainda criança. Conta que, após a perda do irmão, sua mãe retirou das paredes e móveis todas as fotos do irmão, deixando somente aquela. Sua mãe colocou as demais fotos no sótão da casa, a mesma casa agora habitada pelo jovem casal. Evidencia-se a temática que o enredo irá explorar: a dificuldade de lidar com a morte, também expressada no deslocamento das imagens e lembranças dos mortos para o limbo de sótãos pouco frequentados, local da casa distante dos espaços cotidianos e usualmente associado ao passado e 
à memória. A seguir, Ash vai devolver a van sozinho - para nunca mais voltar. O título do episódio tinge-se com um pathos em que se misturam espanto e perplexidade ante a perda abrupta e definitiva. O volto já cotidiano contrasta com o nunca mais voltar da morte, sempre presente no horizonte de possibilidade dos vivos. A promessa contida em todo volto já expressa confiança na vida, no seguir vivendo. Mas também integra o repertório clichê daqueles que estão prestes a abandonar algum parceiro.

A exploração do tema da dificuldade face à finitude passa a ser diretamente desdobrada e confrontada com soluções tecnológicas. No velório, Sara, amiga de Marta, sugere a ajuda de um software que imita o morto, trazendo-o de volta, senão à vida, ao menos ao alcance da conectividade. Sara explica que se antecipou e inscreveu Marta nesse programa, que a ajudara a superar a dor de uma perda semelhante. Marta reage violentamente a essa maneira, segundo ela, doentia de ajuda no luto. Sozinha em casa, pinta e renova objetos, em um movimento sugestivo de seguir em frente. Ao entrar em seu e-mail, observa entretanto que um Ash virtual fez contato. Assustada, mas sem abrir a mensagem, continua navegando na internet. Vê-se na imagem que ela já recebeu sugestões de livros de auto-ajuda para casos de perda e luto.

A moça retoma seu trabalho de webdesigner ou algo no gênero, mas de repente começa a sentir enjoos e a ter crises de vômito. Quando o teste de gravidez dá positivo, a viúva recente entra em crise e procura sua irmã. Não conseguindo falar com ela, cede à tentação de acessar o Ash digital. Acaba por prover o programa com imagens, filmes e falas do marido, arquivadas em seu computador, o que permite a reprodução mais convincente da voz, do jeito e das falas do falecido. Desde que passa a conversar com o programa que emula Ash, Marta não procura mais a ajuda de alguém próximo, furtando-se ao contato efetivo com Nay, a irmã, que vai visitá-la. Ao longo das trocas via e-mail e depois celular, Marta vai aderindo à ficção do outro virtualmente reencontrado, como que devolvido à vida. Contatos on-line realizam certa presença, mitigando o sentimento de isolamento ou solidão. Eis uma solução informática para as dificuldades ante o luto, a morte, a finitude.

O software processa o Ash digital a partir de tudo o que o rapaz havia postado nas redes sociais e registrado em e-mails. A partir de seus rastros digitais, de informações que sobrevivem à vida de seu corpo, Ash ressuscita. O programa comenta com Marta inclusive a estranheza do aspecto fantasmático e espectral desses contatos telefônicos com a voz de um morto. A credibilidade do Ash digital é garantida não apenas por sua voz, mas igualmente pela emulação do humor doce e cáustico, muitas vezes apontado para si mesmo, que caracterizava o rapaz. Por exemplo: no primeiro telefonema, a voz diz a Marta que deve ser estranho ele poder falar, uma vez que já não tem boca - tipo de humor compatível com o que Ash poderia dizer em uma situação como aquela. Ou seja: o software não imita apenas o que o personagem escreveu alguma vez; emula criativamente seu estilo. Quando Marta faz ultrassonografia, ouve o coração do feto e grava o som para enviá-lo a Ash. Entretanto, o celular cai no chão, perde-se o contato e ela se dá conta 
da fragilidade desse modo de substituição. Eis o momento oportuno para o software lhe vender (e bastante caro) uma solução tecnológica ainda mais perfeita e tangível: um corpo biossintético idêntico ao do companheiro morto, capaz de sustentar o programa com mais estabilidade, eficácia e verossimilhança. Marta termina por adquiri-lo.

Entra então em cena outro dispositivo tecnológico, capaz de prover o programa Ash com um novo hardware: um corpo sintético feito à imagem e semelhança do morto. Um corpo já não mortal ou falível. A peça chega em um caixote, meio desmontada, envolta em um líquido que, segundo Marta, tem cheiro parecido com o do esponjoso marshmallow. Segundo explica o programa on-line, trata-se de um gel nutriente colocado no material para que os tecidos não ressequem quando transportados. Para ser ativado e ganhar vida, o material necessita permanecer certo tempo imerso em uma banheira cheia d'água, acrescida de eletrólidos, que Marta compara à ração para peixes de aquário. Enquanto passa pelo procedimento de ativação, emite sons estranhos, surdos, meio borbulhantes. O software Ash (ainda em funcionamento) explica que se trata de um tipo de fermentação. Processos próprios ao mundo orgânico (tanto a solução aquosa quanto a fermentação) são portanto integrados à inorgânica carne sintética. Para a produção de um novo Ash, renascido das cinzas, elementos orgânicos são utilizados para ativar o inorgânico, este último vendido para suprir de modo mais eficaz o vazio deixado pela morte.

O corpo que emerge da banheira, praticamente idêntico ao original, tem algo de inquietantemente robótico ${ }^{1}$. Apesar de imitar quase perfeitamente o rapaz morto, ressuscita mais novo, sem marcas, inexpressivo. Esse quase é importante e irá se intensificar ao longo do episódio. Em sua condição de androide algoritmicamente clonado, assemelha-se a Ash, mas sua expressão facial é menos viva, como se tivesse sido congelada. A pele é macia, lisa, contendo mesmo linhas e simulacros de poros perceptíveis ao tato. Trata-se de uma pele produzida por mapeamento textural, conforme o programa explica para Marta, a não ser em seus detalhes menores, como as pontas dos dedos, duplicadas em 2D. Ou seja: o novo Ash tem pele digitalizada, mas carece de digitais nos dedos, linhas e marcas utilizadas tanto na identidade moderna quanto nas atuais identificações biométricas. A primeira, de modo analógico (por meio da impressão direta das linhas dos dedos); a segunda, traduzida em termos de informação tratada e lida algoritmicamente. A biometria comparece no episódio: quando Marta paga pelo transporte da caixa com as partes do androide, coloca seu dedo em uma máquina de pagamento. Ao fazê-lo, surge sua foto na tela da maquininha, atestando a legitimidade do pagamento. A redução do ser a pacotes informacionais comparece primeiramente em bancos, transações comerciais e controles policiais, de fronteiras.

1 Neste aspecto, o episódio reedita, com diferenças a serem exploradas, o problema do Duplo (Doppelgänger) caro à literatura desde o início do século XIX, com a publicação da novela O homem de areia, de E. T. Hoffmann. Esse texto foi objeto de estudo de Freud no famoso ensaio acerca do conceito de Unheimliche (inquietante familiaridade). Obras de escritores como Edgar A. Poe e Dostoiévski trataram do Duplo. Em que pese a relevância desse tema, neste artigo seguirei outra direção investigativa. 
Quando o casal vai para a cama, aparecem diversas diferenças. Por exemplo, falta uma pinta em seu peito; ela é imediatamente ativada, brotando magicamente de dentro da carne sintética. $O$ androide não entende inicialmente o funcionamento de seu pênis; mas, como tecnologia inteligente, aprende rapidamente. Mesmo sem entender bem, consegue ligá-lo e desligá-lo quando dá o comando. Nesse ponto, o androide de pele macia parece mais performativo, eficaz e competente que os homens de carne, osso e complexa subjetividade. Além de não precisar comer (mas ser capaz de mastigar e engolir para dissimular sua artificialidade), Ash tampouco precisa dormir. Permanece deitado na cama, ao lado de Marta, mas com olhos abertos - outra estranha superioridade sobre os humanos, que (ainda) não podem prescindir do sono ${ }^{2}$ e do esquecimento.

A cena na cama merece destaque. O clone não possuía registro das respostas sexuais de Ash, uma vez que este nada postava acerca de suas experiências íntimas. O estoque de movimentos sexuais do androide provém de vídeos pornô: conforme a reação da parceira sugere, eis outro upgrade em relação ao parceiro perdido. O Ash de carne e osso transava uma vez, virava para o lado e dormia. O desempenho sexual do incansável androide é claramente superior: o casal aparece transando em três posições sexuais diferentes e Marta parece ter mais prazer com o androide. A discrepância entre a fragilidade e limitações próprias ao orgânico e o poder performativo e regenerativo ilimitado do corpo sintético é enfatizada de modo ainda mais explícito na cena em que Ash se fere com um caco de vidro, sem sentir dor. Uma vez retirado o caco, a pele se auto-regenera, como por milagre, imediatamente.

As diferenças entretanto mais significativas, desfavoráveis ao andróide, se dão em outros planos, como o episódio irá mostrar. Em primeiro lugar, semelhante a um autista, o ciber-Ash nem sempre identifica a clivagem entre o literalmente dito e o sentido efetivo. Não decodifica apropriadamente jogos de sentido, que, conforme pleiteou Wittgenstein (2001), só podem funcionar em situações concretas, vividas, imprevisíveis, não programáveis. Por exemplo, quando na cama Marta geme "Oh, no", o robô interpreta tal gemido como índice de que não está agradando, que ela deseja que ele pare, quando obviamente se trata justo do contrário, de uma expressão de prazer. Mas o que passa a irritar especialmente Marta é que o Ash sintético é programado apenas para agradar, nunca entrando em tensão ou em conflito com ela. Obedece, submete-se, nunca reage. Duas cenas são mais marcantes nesse sentido. Em uma delas, Marta repudia o boneco e o agride fisicamente. Ele se nega a devolver a agressão. Ela então sente falta do que o verdadeiro Ash faria. Dizendo que o cordato androide não passa de um nada, expulsa-o de casa. Ao acordar, o vê estancado no portão. Ele explica que não podia se afastar mais de 25 metros de seu ponto de ativação - a mente de Marta e a banheira -, sem colocar em risco a integridade de sua administradora.

2 Jonathan Crary inicia seu livro 24/7 aludindo a pesquisas da Nasa que investigam aves migratórias que conseguem voar por dias seguidos, sem descanso. O autor enfatiza, no capitalismo tardio, o projeto de ultrapassagem dos limites biológicos entre sono e vigília, o novo e inquietante sonho de uma insônia produtiva e performática, a colonização dessa última fronteira humana: o sono (CRARY, 2013). 
A cena mais radical acontece quase na parte final do episódio, quando Marta leva o robô até o Penhasco dos Desesperados (no original Lovers' Leap, salto dos amantes) e ordena que ele pule. $\mathrm{O}$ androide se prontifica a obedecer, mas hesita em fazê-lo, pois não havia registro de impulsos autodestrutivos ou suicidas nos arquivos de Ash. Entretanto, como é programado para satisfazer os desejos de sua proprietária, dispõe-se a realizar o comando e a repetir o trágico salto dos amantes da era vitoriana, conforme a moça explicara sobre o nome dado ao local. Ela então se exaspera, afirmando que o androide não tem história, que é apenas performance. Marta explica que o Ash original teria medo e nunca permaneceria impassível, sem desabar em choro, na iminência de despencar em um precipício. $\mathrm{O}$ androide necessita de poucos segundos para corresponder mais adequadamente à expectativa da moça e emular o humano, chorando e dizendo que não quer morrer. A cena se fecha com Marta, emocionalmente afetada, gritando à beira do abismo um sonoro não.

O episódio tem então seu desfecho: na mesma casa, vemos Marta agora desvitalizada, como que robotizada. Ela festeja o aniversário de sua filha, ruiva como o pai e já bem grandinha. A menina pede para subir até o sótão para levar uma fatia de bolo para Ash. É então explicitada a solução encontrada por Marta: manter o androide no sótão, permitindo a visita da filha nos fins de semana e em datas especiais. Essa solução para a perda repete, em outra chave (não mais como imagens 2D mas em 3 dimensões), o deslocamento para o sótão de lembranças de pessoas mortas, de perdas nunca digeridas ou ultrapassadas, tal como no caso do que a mãe de Ash fizera com relação ao filho perdido. Já não se trata de fotos analógicas em velhos baús, mas do clone que continua ativado no sótão, podendo ser visitado em certos momentos.

Uma vez sintetizado o enredo do episódio Volto já, cabe aprofundar a problemática da perda e da finitude por ele alavancada, explorando de início a concepção de tecnologia em que se baseia e de que modo ela lida com tal questão. Para isso, cabe realizar uma breve incursão pela filosofia que subjaz à tecnociência acionada no episódio. Os trabalhos do sociólogo português Hermínio Martins sobre a filosofia da técnica nos dão pistas férteis nessa direção. Martins identificou uma espécie de gnosticismo tecnológico como impulso operante na tecnociência contemporânea. O gnosticismo tecnológico remete a uma aversão à viscosidade própria ao orgânico, à sua tendência persistente à degradação e à morte, horror expresso tanto na corrente mística (o gnosticismo em sua versão clássica) quanto na agenda atual da tecnociência, em sentido laicizado. Manifesta-se um curioso amálgama entre a invenção de sofisticadas tecnologias digitalizantes e um antigo anseio ocidental de superação dos limites impostos pela materialidade, pela obsolescência programada do orgânico. Mais do que os traços de semelhança entre a visada do gnosticismo em sua versão clássica e a do gnosticismo atrelado às tecnologias, deve-se atentar, entretanto, para uma diferença relevante: na tecnociência, trata-se de uma inclinação destituída de transcendência, conforme veremos. 
O conceito de gnosticismo tecnológico corresponde a um desejo de ascese, por via tecnológica, com relação às imperfeições do orgânico, fadado a todo tipo de disfunção ou falha. Ascese com relação às inevitáveis degradações do corpo e da mente, em seu caráter contingente. Essa noção pode ser articulada ao que Hermínio Martins chamou de impulso fáustico, uma das direções que têm atravessado o desenvolvimento das tecnociências. Remetendo à figura de Fausto, ao pacto com o diabo, esse impulso visa à superação dos limites da vida humana, exprimindo um desejo de esquivar a própria finitude, que implica inevitavelmente (segundo as tecnociências nos prometem, talvez por ora) envelhecimento e morte (FERRAZ, 2000). Esse impulso também pode ser observado no fascínio exercido pela textura lisa e purificada do digital, que os corpos passam a admirar e a querer emular (SIBILIA, 2015).

O horror à viscosidade, às imperfeições, à finitude do orgânico pode ser portanto identificado na redução crescente da corporeidade à pureza da informação digitalizada, da atual genômica às imagens assépticas do interior e do exterior do corpo. Tanto em ressonâncias magnéticas, neuroimagens em vibrantes tons neon, photoshops quanto em imagens chamadas de alta definição no cinema, na televisão digital e também exploradas em publicidades de cosméticos. Manifesta-se igualmente em temas e noções provenientes do campo das neurociências, como a inquietante noção de morte neuronal gradativa (IZQUIERDO, 2002, p. 32), uma morte gradual que teria início, precocemente, tão logo o ser humano realiza sua maior façanha: deixar de engatinhar para adotar a postura bípede. Em uma era destituída de transcendência, o medo de envelhecer, o desejo de superar a finitude e seus sinais por enquanto incontornáveis também se expressam no temor à perda progressiva da memória, remetida ao funcionamento deficiente de redes neuronais do cérebro.

A tecnociência de inflexão fáustica promete ralentar, contornar e no limite esquivar esse ominoso destino orgânico. O conceito de morte neuronal gradativa funciona como uma das novas qualificações da morte, desnaturalizada pelo menos desde 1968, quando emergiu o conceito de morte cerebral, fundamental para novas práticas de reanimação e também para a remoção de órgãos transplantáveis (AGAMBEN, 1998, p. 153-158). Envelhecer e esquecer tornam-se problemas muito precoces, que devem ser mitigados ao longo da vida por toda sorte de fitness cerebral; que devem ser adiados, se não eliminados, por práticas de si aconselháveis, contando também com o auxílio de novos fármacos. Em suma, a inflexão fáustica ancora-se no impulso de superar a limitação e finitude humanas, engendrando um horizonte cultural que está longe de favorecer a experiência, ainda incontornável, do sofrimento, da perda e da morte. De modo geral, o projeto faustiano de gestão total dos mundos orgânico e inorgânico atravessa a tecnociência atual, da bioengenharia à inteligência artificial, passando pela clonagem, pelo avanço das tecnologias reprodutivas e da nanotecnologia. Nessa direção, intensifica-se a manipulação radical da geoesfera e do mundo orgânico. Ao não endossar a finitude, a visão de mundo 
e de vida implicada nesses avanços não nos abastece com um quadro de valores apto a nos preparar para experiências de perda ou luto. Ao contrário, na medida em que se endereça à ultrapassagem dos limites da vida, cria um vácuo, a ser preenchido com fármacos, auto-ajuda e tipos de Ersatz como o androide do episódio.

É essa vertente dominante que está em jogo no episódio comentado. Volto já ressalta os avanços da tecnociência e seus limites. Especialmente no que diz respeito à promessa de superação da contingência e dos sofrimentos humanos. $\mathrm{O}$ androide, tecnologia inteligente muito bem realizada tanto em seu software quanto em seu hardware, não basta para preencher e resolver o vazio deixado pela morte do companheiro. Ao mesmo tempo, tem sua performance aperfeiçoada em vários sentidos, não sente dor, prescinde de comida e de sono. Além de não envelhecer. Seu comportamento é ditado pelo programa que, mesmo capaz de aprender, não o provê com a espessura experiencial própria à subjetividade e necessária à efetiva comunicação. Sua incapacidade para o conflito empobrece e termina por inviabilizar a relação com o outro. Essas duas condições - apenas comportamento, no lugar da vida subjetiva; ausência de rugosidade ou tensão na relação com o outro se expressam na textura especial de sua pele sintética. Essa pele teflon (FERRAZ, 2015, p. 105-114), produzida por mapeamento textural e protegida de rugas ou de ferimentos, carece da porosidade afetiva que caracteriza a pele humana. A fim de dimensionarmos a distância entre a pele sintética do androide e nossa pele, membrana porosa de trocas e comunicação com o mundo, voltemos às origens gregas que se aninham na noção de poros.

Na mitologia grega, Poros e Eros são figuras articuladas entre si. Remetido à ideia de expediente, à saída de situações embaraçosas, Poros é filho de Métis (Astúcia), primeira esposa de Zeus - que a engoliu por temê-la. O nome de Poros foi incorporado ao vocabulário filosófico, que usa o termo aporia (composto por poros acrescido do prefixo privativo a-) para designar situações sem saída, impasses. Filho de Astúcia, Poros, é o expediente, o jeitinho que se encontra como alternativa, como saída para situações complicadas, embaraçosas. Sua inteligência aproximativa, não apenas racionalista, herdada da mãe, foi sistematicamente desqualificada por Platão e Aristóteles, no limiar da filosofia hegemônica no Ocidente (FERRAZ, 1999, p. 81-82).

Sobre a relação entre Poros e Eros, lembremos a versão do mito proposta pela sacerdotisa Diotima, no diálogo platônico O banquete (PLATÃO, 2016). Segundo Diotima, Eros seria um ser intermediário entre os deuses e os homens, nascido da união entre Penia (Pobreza) e Poros (Expediente). Penia não foi convidada para um banquete dos deuses. Ao passar pelo lado de fora dos jardins em que Poros dormia saciado, aproveita-se do sono do belo jovem e engendra Eros. Eros é fruto, portanto, da união (uma união forçada) entre Pobreza e Expediente. Os gregos nos legaram assim esse parentesco algo clandestino entre Eros e Poros.

Ora, se nossa pele é constituída por poros e se é por ela que circulam desejos, o vínculo entre Eros e Poros tem na pele humana sua expressão mais tangível. 
Para aprofundarmos essa temática, dialogaremos com o trabalho do filósofo português José Gil, que tematizou o estatuto paradoxal dessa pele que não apenas habitamos, mas somos. Pensaremos, a seguir, de que modo o bloqueio da porosidade da pele inviabiliza a circulação de Eros tanto em androides como Ash quanto em corpos hiperconectados ou blindados - dos quais Marta se aproxima no final do episódio.

A pele que acreditamos fechar e conter nossos corpos é dotada de um estatuto paradoxal que é oportuno tematizar, no contexto da expansão e consolidação da cultura da imagem, do espetáculo, da performance otimizada e bem-sucedida, bem como nos modos de vida compatíveis com essa ambiência cultural. A pele é meio de comunicação por excelência, uma comunicação direta e não mediada. Trata-se de uma interface dentro/ fora, de uma membrana de trânsito e de trocas com o que costumamos chamar de meio ambiente. Não se trata, portanto, de um mero invólucro ou embalagem. Como lembrou José Gil, em seu livro sobre corpo e dança, a própria sensação de tato se dá, na verdade, milímetros abaixo da pele: "Lembremos que a pele não é uma película superficial, mas tem uma espessura, prolonga-se indefinidamente no interior do corpo: é por isso que a sensação de tato se localiza a alguns milímetros no interior da pele, e não à sua superfície." (GIL, 2001, p. 76, grifo do autor). No livro Metamorfoses do corpo, José Gil explicita essa outra versão de interior ligada aos paradoxos da pele. Eis uma passagem em que o autor recorre a um vocabulário que se esquiva de simplificações espacializantes:

[...] esta zona fronteiriça tem realmente uma interface paradoxal: por um lado limita-se por fora graças à pele; por outro, prolonga o espaço da pele para dentro, conferindo à pele um espaço que a continua, transformando-a: não é já superfície, mas volume ou, mais exatamente atmosfera (GIL, 1997, p. 155, grifos do autor).

Intervém aqui um termo precioso: atmosfera. Essa noção anula e ultrapassa a velha distinção (ainda tão presente) entre corpo e alma, entre corpo e mente ou psiquismo. Em sua materialidade, a pele carreia forças da profundidade do corpo, abrindo-se, ao mesmo tempo, às forças do mundo. Em dimensão paradoxal e membranosa, essa atmosfera ${ }^{3}$ de trocas e comunicação é usualmente recalcada em nossa percepção cotidiana. O esquecimento dos paradoxos da pele articula-se, no Ocidente, à noção literalmente incorporada de indivíduo, que corrobora a oposição entre dentro e fora de que tem sido difícil escapar. Pensar as relações de um corpo com o que estaria fora dele supõe a crença de que nossos corpos próprios seriam isoláveis do entorno (social, natural, cultural), e se comunicariam com o meio a partir dessa separação prévia. Torna-se então inevitável pensar e viver a pele apenas como corte e afastamento entre dentro e fora, como uma fita isolante entre o eu e o mundo. Deixa-se de pensá-la em sua dimensão intrinsecamente comunicacional, como fita de Möbius, interface em que efetivamente circulam trocas de afetos e de forças do e no mundo.

3 Esta noção é sem dúvida inspirada no trabalho de Hubert Damisch acerca das nuvens na história da pintura, mencionado por Gil no livro sobre dança (DAMISCH, 1972; GIL, 2001). 
A partir dessas reflexões, podemos avaliar com mais precisão a distância entre a pele sintética e a pele humana, compreendendo porque o androide Ash não poderia satisfazer o vazio deixado pelo Ash de carne, osso e pele. A impermeabilidade no contato com o outro, a lisura perfeita e incorruptível de sua pele inviabilizariam a circulação de Eros mesmo se, por conta de avanços tecnológicos, o androide viesse a conquistar algo semelhante à plasticidade da subjetividade humana. Ao colocar o clone no sótão e ao passar por cima da efetiva experiência do luto, Marta também se torna impermeável, tem seus poros lacrados e fecha as passagens entre ela, o mundo e a vida. Daí seu aspecto robotizado e amortecido, o olhar triste e esvaziado na cena final. Explicita-se então a questão de fundo: o desfecho melancólico do episódio sugere que é necessário certa coragem existencial e ética para viver perdas, não apenas para suportar a finitude, mas para integrá-la ao viver. Desse movimento depende o viço, a vida, o desejo.

Esse tema está presente na tradição filosófica, comparecendo, por exemplo, de modo vigoroso e mais abrangente, no aforismo de Friedrich Nietzsche (2001) intitulado "Saber encontrar o fim". Como contraponto ao problema detectado no episódio, vale a pena nos determos neste aforismo de Gaia ciência, que amplia a temática até aqui tratada:

\begin{abstract}
Os mestres de primeira ordem dão-se a conhecer pelo fato de, tanto nas coisas grandes como nas pequenas, saberem terminar de modo perfeito, seja uma melodia ou um pensamento, seja o quinto ato de uma tragédia ou uma ação política. Os melhores de segundo nível sempre se inquietam com a aproximação do fim e não descem, por exemplo, para o mar com a orgulhosa e tranquila cadência das montanhas junto a Portofino - lá onde a baía de Gênova termina de cantar sua melodia (NIETZSCHE, 2001, p. 191).
\end{abstract}

Nesse texto, o filósofo distingue o que considera mestres de primeira grandeza a partir deste critério: seriam aqueles que, tanto em situações pequenas como nas grandes, sabem encontrar o fim com perfeição. Um final buscado, tramado, inventado. Não uma fatalidade previamente determinada, mas um desfecho curioso, intrigante. Pelas mãos que sacodem o jogo de dados do acaso, esse desenlace passa a se inscrever como a produção de um destino desejado como tal. Não se trata do sentido usual de destino, como pré-determinação. Eis o que está em jogo: o que se inscreve e se escreve efetua mundos, cria sentidos, traça novas destinações. Esse desfecho de que fala o aforismo citado nada tem de imposto, de inexorável ou fatal. Diante dele, não cabe a máscara lúgubre da vítima que clama por piedade e consolo. O desfecho buscado, tramado de modo perfeito, resolve-se numa declinação musical em direção ao largo, rumo ao mar. Nele ressoam altivez e serenidade, certa linha de sobriedade. No aforismo, Nietzsche enumera a amplitude de campos em que saber terminar seria prova de maestria de primeira ordem. Pode se tratar do fim de uma melodia, de um pensamento, do quinto ato de uma tragédia ou de uma ação política. É portanto necessário, em vários sentidos, intensificar a arte de saber terminar, de saber encontrar novos fins, desenlaces inventivos. Tudo está sempre em jogo nessa arte. 
O filósofo acrescenta que os melhores de segunda grandeza se inquietam cada vez mais à medida que se vai aproximando o fim. A angústia diante do fim, tomada como inevitável pelo senso comum e em determinadas perspectivas filosóficas, seria sentida, conforme Nietzsche, por mestres de segunda; haveria nela algo de humano, demasiado humano. Essa angústia secreta um pathos que caracteriza os que não possuem a força vital necessária para encarar o fim como uma nova chance para o mais perfeito golpe de mestre. A verdadeira maestria expressa-se na destemida arte de achar um fim, fluindo ativamente nessa direção, metamorfoseando os momentos finais em uma nova oportunidade para a criação de desfechos imprevisíveis, surpreendentes.

Nesse momento do texto, expressão da arte retórica como potente arma para superar a angústia e inquietação ante o fim (e não consolar), emerge uma imagem geográfica, uma ode por assim dizer geológica: a referência à impactante beleza das montanhas e do litoral de Portofino, perto de Gênova. O aforismo conclui-se de modo performativo, fazendo aquilo que diz. Em seu desfecho, alcança uma rítmica, uma musicalidade visual, quase pictórica, de alta maestria: "descem, por exemplo, para o mar com a orgulhosa e tranquila cadência das montanhas junto a Portofino - lá onde a baía de Gênova termina de cantar sua melodia". A tradução é bem realizada; o original alemão pauta-se por uma cadência rítmica dotada de uma força de encantamento e de persuasão ainda mais notável. O movimento de descida torna-se de fato melódico. A cadeia de montanhas deita-se no mar. Nessa cadência, não se expressa qualquer resignação perante o fim; produz-se, de modo ativo, um movimento em que a beleza plástica funde-se à musicalidade, enunciando uma serena e sóbria celebração da finitude aliada ao devir.

Podemos então concluir que certas perspectivas já um tanto esquecidas na cultura contemporânea, e que a visão fáustica da tecnociência não pode abrigar, exprimem-se nesse convite à afirmação do fim, encarado como uma oportunidade para a criação de uma resposta de outra ordem, ético-estética, à questão da finitude. Logo, como uma cura para a doença mais aguda que, em sua obra, Nietzsche identificou em nossa cultura e para a qual o episódio Be right back não deixa de apontar: o ressentimento contra o tempo, por ele não cessar de estar passando e ser irreversível. Na medida em que a cultura do espetáculo contemporânea não cessa de valorizar imagens de felicidade estampadas na superfície dos rostos e que o temor ao perecível orgânico tende a obstruir os poros da pele, essa experiência afirmadora e inventiva a partir do sofrimento e do luto está longe de ser favorecida. Só ela, entretanto, parece apta a propiciar a abertura dos poros, a circulação de Eros e, por fim, um pathos muito mais sutil, passageiro, nem um pouco espetacular: a alegria. Que Guimarães Rosa, no desfecho do conto As margens da alegria, remete à intermitência luminosa própria aos vagalumes: "Sim, o vagalume, sim, era lindo! tão pequenino, no ar, um instante só, alto, distante, indo-se. Era, outra vez em quando, a Alegria" (ROSA, 1969, p. 7). 
Maria Cristina Franco Ferraz é professora titular da ECO/ UFRJ, pesquisadora do CNPq, doutora em Filosofia pela Universidade de Paris I - Sorbonne (1992), com três estágios de pós-doutoramento em Berlim (Instituto Max Planck de História da Ciência, em 2004, e Centro de Pesquisa em Literatura e Cultura, em 2007 e 2010). Coordena na UFRJ o Mestrado Internacional Erasmus + "Crossways in Cultural Narratives". Publicou os livros: Nietzsche, o bufão dos deuses (Rio: Relume Dumará, 1994; Paris: Harmattan, 1998; Segunda edição ampliada: SP: n-1, 2017), Platão: as artimanhas do fingimento (Rio: Relume Dumará, 1999 e Lisboa: Nova Vega, 2010), Nove variações sobre temas nietzschianos (Rio: Relume Dumará, 2002), Homo deletabilis - corpo, percepção, esquecimento: do século XIX ao XXI (Rio: Garamond/FAPERJ, 2010), Ruminações: cultura letrada e dispersão hiperconectada (Rio: Garamond/ FAPERJ, 2015) e L'homme effaçable: mémoire et oubli du XIXe siècle à nos jours (Paris: Hermann, 2015).

mcfferraz@hotmail.com

\section{Referências}

AGAMBEN, G. O poder soberano e a vida nua: homo sacer. Lisboa: Editorial Presença, 1998.

CRARY, J. 24/7 - late capitalism and the ends of sleep. Londres/Nova York: Verso, 2013.

DAMISCH, H. Théorie du nuage (pour une histoire de la peinture). Paris: Editions du Seuil, 1972.

FERRAZ, M. C. F. Platão: as artimanhas do fingimento. Rio de Janeiro: Ed. Relume Dumará, 1999. 2015.

Ruminações: cultura letrada e dispersão hiperconectada. Rio de Janeiro: Garamond/FAPERJ,

Sociedade tecnológica: de Prometeu a Fausto. Revista Contracampo, Niterói, n. 4, p. 117 124 , jan. 2000.

GIL, J. Metamorfoses do corpo. Lisboa: Relógio d'Água, 1997.

Movimento total - O corpo e a dança. Lisboa: Relógio d'Água, 2001.

IZQUIERDO, I. Memória. Porto Alegre: Artmed, 2002.

MARTINS, H. Experimentum Humanum: civilização tecnológica e condição humana. Belo Horizonte: Fino Traço, 2012.

Hegel, Texas e outros ensaios em teoria social. Lisboa: Ed. Século XXI, 1996.

NIETZSCHE, F. A gaia ciência. São Paulo: Companhia das Letras, 2001.

PLATÃO. O banquete. São Paulo, Ed. 34, 2016. 
ROSA, G. Primeiras estórias. Rio de Janeiro: José Olympio Ed., 1969.

SIBILIA, P. O homem pós-orgânico: a alquimia dos corpos e das almas à luz das tecnologias digitais. Rio de Janeiro: Contraponto, 2015.

WITTGENSTEIN, L. Philosophische Untersuchungen/Philosophical investigations. Malden/Oxford/ Victoria: Blackwell Publishing Ltd, 2001. 